\title{
USO DEADITIVOS QUÍMICOS PARA A CONSERVAČ̃̃O PÓS-COLHEITA DE BANANA 'MAÇÃ' MINIMAMENTE PROCESSADA
}

\author{
Use of chemical additives for postharvest conservation of fresh cut 'Apple' Banana
}

\author{
Anderson Adriano Martins Meloํ, Eduardo Valério de Barros Vilas Boas², Cristina Filomena Justo ${ }^{3}$
}

\begin{abstract}
RESUMO
Objetivou-se, neste trabalho, estudar o efeito de tratamentos com ácido ascórbico (AA), cloreto de cálcio (CC) e cloridrato de L-cisteína (LC) sobre a qualidade pós-colheita de banana 'Maçã' minimamente processada. Foram testadas as seguintes combinações: 1 (Controle); 2 (AA 1\%); 3 (CC 1\%); 4 (LC 0,5\%); 5 (AA 1\% + CC 1\%); 6 (AA 1\% + LC 0,5\%); 7 (CC 1\% + LC 0,5\%); 8 (AA 1\% + CC $1 \%+\mathrm{LC} 0,5 \%)$. As bananas foram descascadas, fatiadas e imersas nos tratamentos, acondicionadas em bandejas, que foram envolvidas em filme de PVC $30 \mu \mathrm{m}$, e armazenadas a $5 \pm 1^{\circ} \mathrm{C}$ e $90 \pm 3 \%$ UR, durante 4 dias. As avaliações ocorreram nos dias $0,1,2$ e 4. Houve um aumento na perda de massa durante o tempo de armazenamento, menor no tratamento 8 em relação aos demais. A acidez total titulável aumentou linearmente com o tempo em todos os tratamentos. A perda de firmeza foi mais eficientemente contida nas fatias sob os tratamentos com cloreto de cálcio. A formação de uma coloração vermelho-rósea sobre as fatias tratadas com Lcisteína foi observada e evidenciada pelos maiores valores de $\mathrm{a}^{*}$. $\mathrm{O}$ valor $\mathrm{L}^{*} \mathrm{e} o$ índice de escurecimento também foram afetados pelo tratamento com L-cisteína, cujo decréscimo nesses parâmetros de cor foi maior nas fatias não-tratadas, ao longo do tempo. O tratamento de banana 'Maçã' minimamente processada com a combinação AA $1 \%$ + CC $1 \%$ + LC 0,5\% foi eficiente para manutenção da sua qualidade pós-colheita.
\end{abstract}

Termos para indexação: Processamento mínimo, Musa spp., cloreto de cálcio, cisteína, ácido ascórbico.

\begin{abstract}
This work had the aim of studying the effect of treatments with ascorbic acid (AA), calcium chloride (CC) and L-cysteine hydrochloride (LC) on the postharvest quality of fresh-cut 'Apple' banana. The following combinations were tested: 1 (Control); 2 (AA 1\%); 3 (CC 1\%); 4 (LC 0.5\%); 5 (AA 1\% + CC 1\%); 6 (AA 1\% + LC 0.5\%); 7 (CC 1\% + LC 0.5\%); 8 (AA 1\% + CC 1\% + LC $0.5 \%)$. The bananas were peeled, sliced and immersed into the treatments, conditioned on trays, which were wrapped with $30 \mu \mathrm{m}$ PVC film, and stored at $5 \pm 1{ }^{\circ} \mathrm{C}$ and $90 \pm 3 \% \mathrm{RH}$, during 4 days. Evaluations occurred at $0,1,2$ and 4 days. There was an increase in the mass loss during the storage period, lower in the treatment 8 in relation to the others. Total titratable acidity increased linearly throughout the time in all treatments. The loss of firmness was prevented more efficiently in the treatments with calcium chloride. A pinkish-red color formation on the slices treated with L-cysteine was observed and evidenced by the highest values of $\mathrm{a}^{*}$. The $\mathrm{L}^{*}$ value and the browning index were also affected by the treatments containing L-cysteine, whose decrease in these color parameters was higher in the untreated slices throughout the time. The treatment of fresh-cut 'Apple' banana with the combination AA $1 \%+\mathrm{CC}$ $1 \%+\mathrm{LC} 0.5 \%$ was efficient for its postharvest quality maintenance.
\end{abstract}

Index terms: Minimal processing, postharvest, Musa spp., calcium chloride, cysteine, ascorbic acid.

(Recebido em 18 de maio de 2006 e aprovado em 22 de agosto de 2007)

\section{INTRODUÇÃo}

O processamento mínimo caracteriza-se por uma série de eventos, como sanitização, descascamento, corte e/ ou abrasões, que promovem a conveniência de consumo de frutas e hortaliças, às expensas da redução de sua vida útil pós-colheita. $\mathrm{O}$ corte dos tecidos descompartimentaliza células, favorecendo a atividade de enzimas que causam o escurecimento e o amaciamento dos tecidos.

A banana minimamente processada constitui uma interessante opção para compor saladas de frutas. Além disso, o processamento mínimo, que exige o emprego de baixas temperaturas, freqüentemente aliado ao uso de atmosfera modificada, parece permitir aumento da vida de prateleira desse tipo de produto.

Os compostos sulfurados têm sido empregados para redução do escurecimento enzimático de vegetais minimamente processados (KAHN, 1985). A cisteína tem sido utilizada com eficácia na conservação de banana (MELO \& VILAS-BOAS, 2006, 2007), maçãs e batatas (MOLNAR-PEARL \& FRIEDMAN, 1990; ROCCULI et al., 2007). Três diferentes mecanismos de atuação de cisteína

\footnotetext{
Engenheiro Agrônomo, Doutorado em Fisiologia Vegetal - Departamento de Biologia Vegetal/DBV - Universidade Federal de Viçosa/UFV - Avenida Ph Rolfs, s/n - 36570-000 - Viçosa, MG - melo.anderson@yahoo.com.br

'Engenheiro Agrônomo, Doutor, Professor - Departamento de Ciência dos Alimentos/DCA - Universidade Federal de Lavras/UFLA - Cx. P. 3037 37200-000 - Lavras, MG - evbvboas@ufla.br

${ }^{3}$ Bióloga, Doutora, Professora - Departamento de Ciências Biológicas e da Saúde - Universidade Federal de Mato Grosso/UFMT - Rodovia MT-100, Km 3 78698-000 - Pontal do Araguaia, MT - cfjusto@uol.com.br
} 
são propostos: redução das o-quinonas a o-dihidroxifenóis (KAHN, 1985); inibição direta da atividade da polifenoloxidase (DUDLEY \& HOTCHKISS, 1989) e reação com o-quinonas dando origem a compostos incolores cisteína-quinona, inibidores competitivos da polifenoloxidase (RICHARD-FORGET et al., 1992).

O ácido ascórbico é reconhecido por sua ação redutora e contribuição nutricional (vitamina $\mathrm{C}$ ). Esse ácido e seus sais neutros são os principais antioxidantes para o uso em frutas e hortaliças e seus sucos, visando prevenir escurecimento e outras reações oxidativas (WILEY, 1994). Ele atua seqüestrando o cobre, cofator enzimático da polifenoloxidase, e também reduzindo quinonas de volta a fenóis, antes de formarem pigmentos escuros (SAPERS \& MILLER, 1998). O ácido ascórbico tem sido utilizado com eficácia para evitar o escurecimento enzimático de batatas (BUTA \& MOLINE, 2001; ROCCULI et al., 2007), abacaxis (GONZÁLEZ-AGUILAR et al., 2004), pêras (GORNY et al., 2002), entre outros.

Os agentes quelantes não são antioxidantes, todavia desempenham um importante papel na estabilização de alimentos (DZIEZAK, 1986). O EDTA é um potente agente quelante, capaz de formar complexos altamente estáveis pela ação seqüestrante desse composto sobre o $\mathrm{Fe}^{2+} \mathrm{o} \mathrm{Cu}^{2+} \mathrm{e} o$ $\mathrm{Ca}^{2+}$, em que ocorre a formação de anéis, através de ligações desses íons ao par de elétrons dos nitrogênios e ao par de elétrons livres do grupo carboxílico, (FENNEMA, 1993). Assim, o uso do EDTA poderia reduzir a atividade da PFO, pela quelatação do cobre.

O íon cálcio, amplamente empregado na conservação de frutas e hortaliças pós-colheita, torna firmes as células dos tecidos dos frutos e hortaliças por reagir com o ácido péctico para formar pectato de cálcio (KING JUNIOR \& BOLIN, 1989). O cloreto de cálcio tem mostrado efeitos positivos quando aplicado por imersão em frutos e hortaliças, minimamente processados. Huxsoll \& Bolin (1989) observaram efeito positivo do cálcio na manutenção da firmeza e na prevenção do escurecimento de fatias de pêssegos. O cálcio mostrou-se também eficaz na retenção da firmeza de bananas das cultivares Maçã (MELO \& VILAS-BOAS, 2007) e 'Grand Naine' (VILASBOAS \& KADER, 2006), minimamente processadas.

Objetivou-se, neste trabalho avaliar o efeito do $\mathrm{CaCl}_{2}$, do ácido ascórbico e do cloridrato de L-cisteína, isolados em combinações, sobre a manutenção da qualidade póscolheita de bananas 'Maçã', minimamente processadas.

\section{MATERIALE MÉTODOS}

Bananas da cultivar Maçã, provenientes do mercado varejista local, tiveram os buquês selecionados segundo homogeneidade de cor (grau de coloração da casca 6 - totalmente amarela) (KADER, 2008), tamanho, ausência de defeitos.

Os buquês foram conduzidos ao Laboratório de Fisiologia Pós-colheita da Universidade Federal de Lavras, e armazenados em câmara fria $14^{\circ} \mathrm{C}$ por 12 horas. Logo após, foram lavados em solução de água e sabão neutro e, em seguida, mergulhados em água fria $\left(10^{\circ} \mathrm{C}\right)$ contendo solução de hipoclorito de sódio 500 ppm, por 15 minutos. Posteriormente, foram descascados e fatiados em espessura de aproximadamente $2 \mathrm{~cm}$. As fatias foram mergulhadas por 3 minutos nas soluções contendo os seguintes tratamentos químicos: 1: controle; 2: ácido ascórbico (AA) 1\%; 3: cloreto de cálcio (CC) 1\%; 4: cloridrato de L-cisteína (LC) $0,5 \%$; 5 : AA $1 \%$ + CC $1 \%$; 6: AA $1 \%$ LC $0,5 \%$; 7 : CC $1 \%$ $+\mathrm{LC} 0,5 \% ; 8$ : AA $1 \%+\mathrm{CC} 1 \%+\mathrm{LC} 0,5 \%$. Em seguida, as fatias foram acondicionadas em bandejas de polipropileno contendo aproximadamente $120 \mathrm{~g}$ de frutos, que foram recobertas por filme de $\mathrm{PVC}$ de $30 \mu \mathrm{m}$, pesadas e imediatamente armazenadas em câmara fria $\left(5 \pm 1^{\circ} \mathrm{C}\right.$ e $90 \pm$ $3 \%$ UR) durante 4 dias. As avaliações ocorreram nos dias $0,1,2$ e 4 .

A determinação da perda de massa ocorreu por meio de pesagem em balança semi-analítica, modelo Mettler PC 2000. Foi considerada a diferença de peso entre a bandeja no tempo considerado, e sua pesagem no tempo 0 dia, sendo os resultados expressos em porcentagem.

A firmeza foi mensurada com auxílio de um analisador de textura, modelo TA-XT2i (Stable Micro Systems Ltd.). Foram realizadas 10 medições por parcela, utilizando em todas as leituras a ponteira $\mathrm{P} / 2 \mathrm{~N}$, com velocidades de $4 \mathrm{~mm} . \mathrm{s}^{-1}$ (pré-teste), $2 \mathrm{~mm} . \mathrm{s}^{-1}$ (teste), e 8 $\mathrm{mm} \cdot \mathrm{s}^{-1}$ (pós-teste); e profundidade de penetração de $5 \mathrm{~mm}$. Os resultados foram expressos em Newton (N).

Os sólidos solúveis totais foram aferidos com uso de refratômetro digital, modelo PR-100 (ATAGO) com compensação de temperatura automática a $25^{\circ} \mathrm{C}$, e os resultados expressos em ${ }^{\circ}$ Brix, segundo AOAC (1992).

A determinação da acidez total titulável ocorreu por meio da titulação do homogenato dos frutos previamente filtrado em organza, utilizando-se $\mathrm{NaOH} 0,1 \mathrm{~N}$ até $\mathrm{pH} 8,2$, de acordo com método da AOAC (1992), sendo os resultados expressos em gramas de ácido málico/100 mL de suco.

$\mathrm{O}$ pH foi medido com potenciômetro digital, modelo DMpH-2 (Digimed) (AOAC, 1992).

Para a análise colorimétrica dos frutos foi utilizado um colorímetro (Minolta CR300 - Ramsey, N.Y., U.S.A.), seguindo modelo tridimensional de coordenadas cromáticas, preconizado pelo $\mathrm{CIE}\left(\mathrm{L}^{*} \mathrm{a}^{*} \mathrm{~b}^{*}\right)$. $\mathrm{O}$ valor de 
$\mathrm{L}^{*}$ representa a luminosidade da cor (0 indica preto e 100 indica branco), e foi utilizado como um indicativo do escurecimento das superfícies cortadas, conforme Gorny et al. (2002). A coordenada a* indica a posição da cor entre verde (-a) e vermelho (+a), e a coordenada $b^{*}$ entre azul (-b) e amarelo (+b). O índice de escurecimento (IE) foi calculado segundo o modelo proposto por Palou et al. (1999): IE= $[100(x-0,31) / 0,172]$, onde, $x=(a+1,75 L) /(5,645 L+a-3,012 b)$.

$\mathrm{O}$ experimento foi conduzido em delineamento inteiramente casualizado (DIC), em esquema fatorial $8 \times 4$, sendo 8 tratamentos químicos e quatro tempos de armazenamento ( $0,1,2$, e 4 dias) com três repetições, sendo a parcela experimental constituída de uma bandeja de fatias. Os resultados foram submetidos à análise de variância sendo as médias, quando significativas, comparadas pelo teste de Tukey, a 5\% de probabilidade.

\section{RESULTADOS E DISCUSSÃO}

A perda de massa foi significativamente afetada pelos tratamentos e pelo período de armazenamento, bem como pela interação entre esses fatores (Tabela 1). O controle exibiu a maior perda de massa em todos os dias avaliados, bem como a maior média geral. $\mathrm{O}$ tratamento 8 determinou o menor porcentual médio de perda de massa entre o 3-o o 4 dias de armazenamento e também a menor média geral que os demais, evidenciando que a tríplice combinação foi mais efetiva na contenção da perda de firmeza das fatias.

Segundo Yang \& Hoffmann (1984), a perda da massa é um dos principais fatores na vida de armazenamento de muitos produtos hortícolas, sendo função do tempo de armazenamento e da transpiração. Em frutos minimamente processados, o corte aumenta a sua relação superfície/volume e expõe o tecido à atmosfera, potencializando a perda de água, e conseqüente perda de massa fresca. No entanto, apesar das significativas diferenças ocorridas entre os tratamentos, a perda de massa observada neste trabalho foi mínima, não atingindo $0,5 \%$. Em termos práticos, não comprometeu a qualidade final do produto aos 4 dias de armazenamento. A atmosfera modificada passiva, com uso de filme de PVC, contribuiu para reduzir o déficit de pressão de vapor d'água entre as fatias e a atmosfera no interior da embalagem, minimizando a perda de massa.

A firmeza das fatias foi significativamente afetada pela interação entre o tempo de armazenamento e os tratamentos utilizados. Houve acentuada redução nessa variável durante o armazenamento, sendo mais significativa em todos os tratamentos que não utilizaram $\mathrm{CaCl}_{2}$ na mistura química. (Figura 1).

Melo \& Vilas-Boas (2007) e Vilas-Boas \& Kader (2006) também verificaram eficiência do tratamento com $\mathrm{CaCl}_{2}$ sobre a firmeza de bananas minimamente processadas. Varoquaux et al. (1990) sugerem que as mudanças na firmeza de kiwis minimamente processados durante o armazenamento se deve à hidrólise das paredes celulares. As enzimas pectinolíticas e proteolíticas difundem-se através do tecido fatiado, proporcionando o seu amaciamento. Segundo Poovaiah (1986), o cálcio interage com a pectina da parede celular de frutos, mantendo a sua estrutura, proporcionando uma textura mais firme a eles. Assim, a maior firmeza observada nas fatias tratadas com $\mathrm{CaCl}_{2}$ pode ser atribuída ao papel do cálcio como cátion ligante entre resíduos de ácido galacturônico, formando pectato de cálcio, que torna mais rígida a estrutura da pectina na lamela média entre paredes celulares adjacentes, e desse modo, confere textura mais firme ao tecido.

Tabela 1 - Médias da perda de massa (\%) de banana 'Maçã' minimamente processada durante o armazenamento a $5^{\circ} \mathrm{C}$ por 4 dias.

\begin{tabular}{|c|c|c|c|c|}
\hline Tratamento & $1 \mathrm{dia}$ & 2 dias & 4 dias & Média \\
\hline 1 - Controle & $0,271 \mathrm{c}$ & $0,396 \mathrm{~d}$ & $0,477 \mathrm{~d}$ & $0,381 \mathrm{D}$ \\
\hline 2 - AA $1 \%$ & $0,205 \mathrm{ab}$ & $0,315 \mathrm{c}$ & $0,428 \mathrm{c}$ & $0,316 \mathrm{C}$ \\
\hline $3-\mathrm{CC} 1 \%$ & $0,199 \mathrm{ab}$ & $0,255 \mathrm{a}$ & $0,343 \mathrm{~b}$ & $0,266 \mathrm{~B}$ \\
\hline $4-\mathrm{LC} 0.5 \%$ & $0,205 a b$ & $0,254 \mathrm{ab}$ & $0,347 \mathrm{~b}$ & $0,269 \mathrm{~B}$ \\
\hline $5-\mathrm{AA} 1 \%+\mathrm{CC} 1 \%$ & $0,225 \mathrm{~b}$ & $0,286 \mathrm{abc}$ & $0,349 \mathrm{~b}$ & $0,286 \mathrm{BC}$ \\
\hline $6-\mathrm{AA} 1 \%+\mathrm{LC} 0,5 \%$ & $0,203 \mathrm{ab}$ & $0,295 \mathrm{bc}$ & $0,383 \mathrm{bc}$ & $0,294 \mathrm{BC}$ \\
\hline $7-\mathrm{CC} 1 \%+\mathrm{LC} 0,5 \%$ & $0,207 \mathrm{~b}$ & $0,326 \mathrm{c}$ & $0,381 \mathrm{~b}$ & $0,305 \mathrm{C}$ \\
\hline $8-\mathrm{AA} 1 \%+\mathrm{CC} 1 \%+\mathrm{LC} 0,5 \%$ & $0,160 \mathrm{a}$ & $0,259 \mathrm{ab}$ & $0,283 \mathrm{a}$ & $0,234 \mathrm{~A}$ \\
\hline
\end{tabular}

Médias seguidas de mesmas letras na coluna não diferem entre si pelo teste de Tukey, a 5\%. 


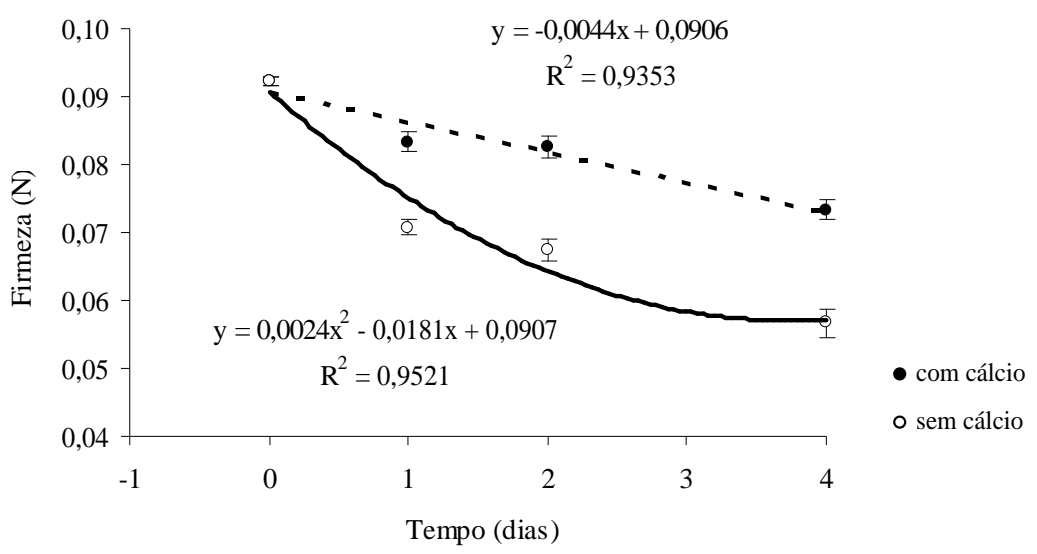

Figura 1 - Valores médios de firmeza dos tratamentos com cálcio e sem cálcio de banana 'Maçã' minimamente processada submetida aos seguintes tratamentos: controle; ácido ascórbico (AA) 1\%; cloreto de cálcio (CC) 1\%; cloridrato de Lcisteína (LC) 0,5\%; AA 1\% + CC 1\%; AA 1\% + LC 0,5\%; CC 1\% + LC 0,5\%; e AA 1\% + CC 1\% + LC 0,5\%, armazenada a $5 \pm 11^{\circ} \mathrm{C}$ e $90 \pm 3 \% \mathrm{UR}$, por 4 dias. Barras verticais representam o erro padrão das médias.

Houve efeito significativo do tempo de armazenamento, dos tratamentos, e da interação desses fatores sobre a variável sólidos solúveis totais (SST) (Tabela 2), que aumentou em todos os tratamentos com o tempo. Segundo Vilas-Boas et al. (2001), uma das mais flagrantes modificações durante o amadurecimento de bananas é a hidrólise do amido que culmina com o acúmulo de açúcares e adoçamento da polpa. No entanto, para o tratamento-controle, observou-se um comportamento ligeiramente distinto, de elevação no teor de SST até o $2^{\circ}$ dia, seguido de queda até o 4o dia. Esse resultado provavelmente se deve ao efeito da ausência de tratamento químico que permitiu maior taxa respiratória, e conseqüentemente um maior consumo de SST como substrato respiratório, nesse período.

A média de SST observada (19\%), para bananas no estádio 6 de maturação, é menor do que a observada por Pinheiro et al. (2003), que trabalharam com bananas 'Maçã' inteiras e observaram teor de $27,3 \%$, porém no grau 7 de coloração da casca. Entretanto, para banana minimamente processada, o menor grau de coloração da casca pode determinar maior vida pós-colheita, sem prejuízo para o conteúdo de sólidos solúveis totais.

A acidez total titulável (ATT) foi influenciada pelos diferentes tratamentos, e aumentou linearmente com o período de armazenamento (Figura 2). Segundo Wills et al. (1981), o teor de ácidos orgânicos reduz com a maturação dos frutos, sendo a banana uma exceção, onde os maiores níveis de ATT são obtidos com os frutos completamente maduros.
Pinheiro et al. (2003) observaram média de 0,47\% de ácido málico em bananas 'Maçã' no grau 7 de coloração da casca e Reis et al. (2004), verificaram valores de ATT para banana 'Prata' minimamente processada no intervalo de $0,39 \%$ a $0,42 \%$, condizente com os encontrados neste trabalho, cujos frutos encontravam-se no estádio 6 de coloração da casca, portanto em fase final de maturação, o que explica o aumento observado da ATT.

$\mathrm{O}$ pH aumentou com o tempo, sendo esse aumento distinto entre tratamentos (Figura 3 A). Apesar de tal variação ter sido muito pequena, o tratamento somente com ácido ascórbico determinou a maior média de $\mathrm{pH}$, diferenciando-se significativamente apenas do tratamento 8 , que envolveu a mistura de todos os compostos químicos, com menor valor de pH. Melo \& Vilas-Boas (2006) também observaram aumento no $\mathrm{pH}$ de banana 'Maçã' minimamente processada, tratada com misturas químicas de ácido ascórbico, cloreto de cálcio e cisteína.

A variação do $\mathrm{pH}$ mostrou comportamento parabólico (Figura $3 \mathrm{~B}$ ), com declínio até as primeiras 24 horas e posterior aumento, até os 4 dias de armazenamento. Esse comportamento pode ser explicado pelo fato de que as bananas avaliadas no tempo 0 dias (logo após o corte) ainda não haviam sido imersas nas soluções antioxidantes, as quais possuem caráter ácido.

Não foi observada correlação entre a acidez total titulável e o $\mathrm{pH}$, provavelmente devido a um efeito tampão conferido pelos baixos teores de ácidos orgânicos encontrados na banana (que variou de 0,31 a $0,37 \%$ ); segundo Chitarra \& Chitarra (1990), isso é possível quando os teores de ácidos totais tituláveis são menores do que $0,5 \%$. 
MELO, A. A. M. et al.

Tabela 2 - Valores médios de SST ( ${ }^{\circ}$ Brix) de banana 'Maçã' minimamente processada durante o armazenamento a $5^{\circ} \mathrm{C}$ por 4 dias.

\begin{tabular}{lccccc}
\hline \multicolumn{1}{c}{ Tratamento } & 0 dia & 1 dia & 2 dias & 4 dias & Média \\
\hline 1 - Controle & $18,33 \mathrm{a}$ & $19,50 \mathrm{~b}$ & $20,00 \mathrm{~b}$ & $19,17 \mathrm{a}$ & $19,25 \mathrm{~b}$ \\
2 - AA 1\% & $18,33 \mathrm{a}$ & $18,67 \mathrm{ab}$ & $18,83 \mathrm{a}$ & $20,17 \mathrm{a}$ & $19,00 \mathrm{ab}$ \\
3 - CC 1\% & $18,33 \mathrm{a}$ & $18,67 \mathrm{ab}$ & $18,83 \mathrm{a}$ & $20,00 \mathrm{a}$ & $18,96 \mathrm{ab}$ \\
4 - LC 0.5\% & $18,33 \mathrm{a}$ & $18,83 \mathrm{ab}$ & $19,00 \mathrm{ab}$ & $20,17 \mathrm{a}$ & $19,08 \mathrm{ab}$ \\
5 - AA 1\%+ CC 1\% & $18,33 \mathrm{a}$ & $18,50 \mathrm{ab}$ & $19,00 \mathrm{ab}$ & $20,17 \mathrm{a}$ & $19,00 \mathrm{ab}$ \\
6 - AA 1\%+ LC 0,5\% & $18,33 \mathrm{a}$ & $18,67 \mathrm{ab}$ & $19,00 \mathrm{ab}$ & $20,00 \mathrm{a}$ & $19,00 \mathrm{ab}$ \\
7 - CC 1\%+ LC 0,5\% & $18,33 \mathrm{a}$ & $18,67 \mathrm{ab}$ & $18,83 \mathrm{a}$ & $20,00 \mathrm{a}$ & $18,96 \mathrm{ab}$ \\
8 - AA 1\%+ CC 1\%+ LC 0,5\% & $18,33 \mathrm{a}$ & $18,33 \mathrm{a}$ & $18,83 \mathrm{a}$ & $19,33 \mathrm{a}$ & $18,71 \mathrm{a}$ \\
\hline
\end{tabular}

Médias seguidas de mesmas letras na coluna não diferem entre si pelo teste de Tukey, a 5\%.
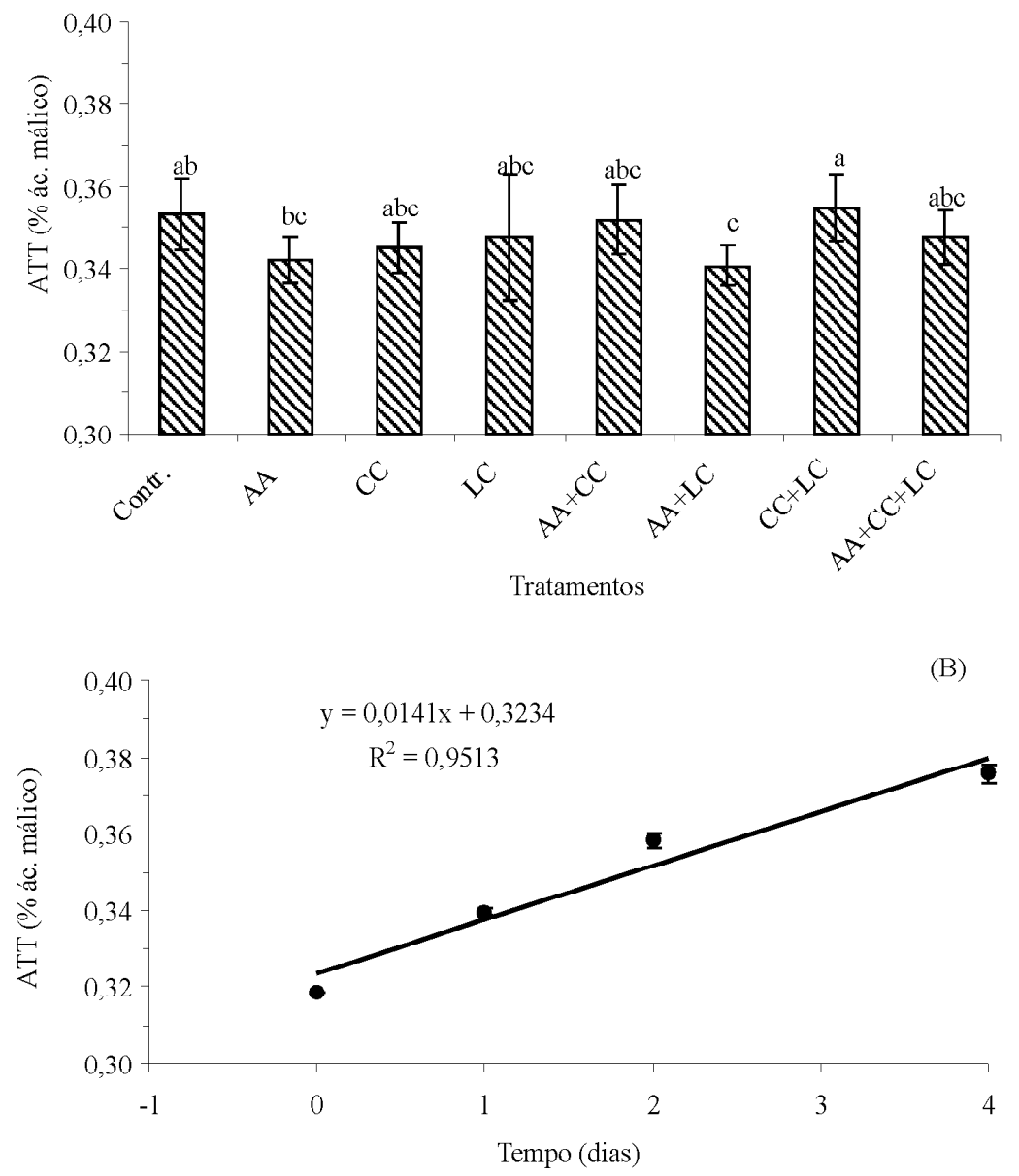

Figura 2 - Valores médios observados de ATT de banana 'Maçã' minimamente processada submetida a diferentes tratamentoscontrole; ácido ascórbico (AA) 1\%; cloreto de cálcio (CC) 1\%; cloridrato de L-cisteína (LC) 0,5\%; AA 1\% + CC 1\%; AA 1\% + LC 0,5\%; CC 1\% + LC 0,5\%; eAA 1\% + CC 1\% + LC 0,5\%, armazenada a $5 \pm 1{ }^{\circ} \mathrm{C} \mathrm{e} 90 \pm 3 \%$ UR, por 4 dias. Barras verticais representam o erro-padrão das médias. Letras iguais não diferem entre si pelo teste de Tukey, a 5\% de probabilidade. 

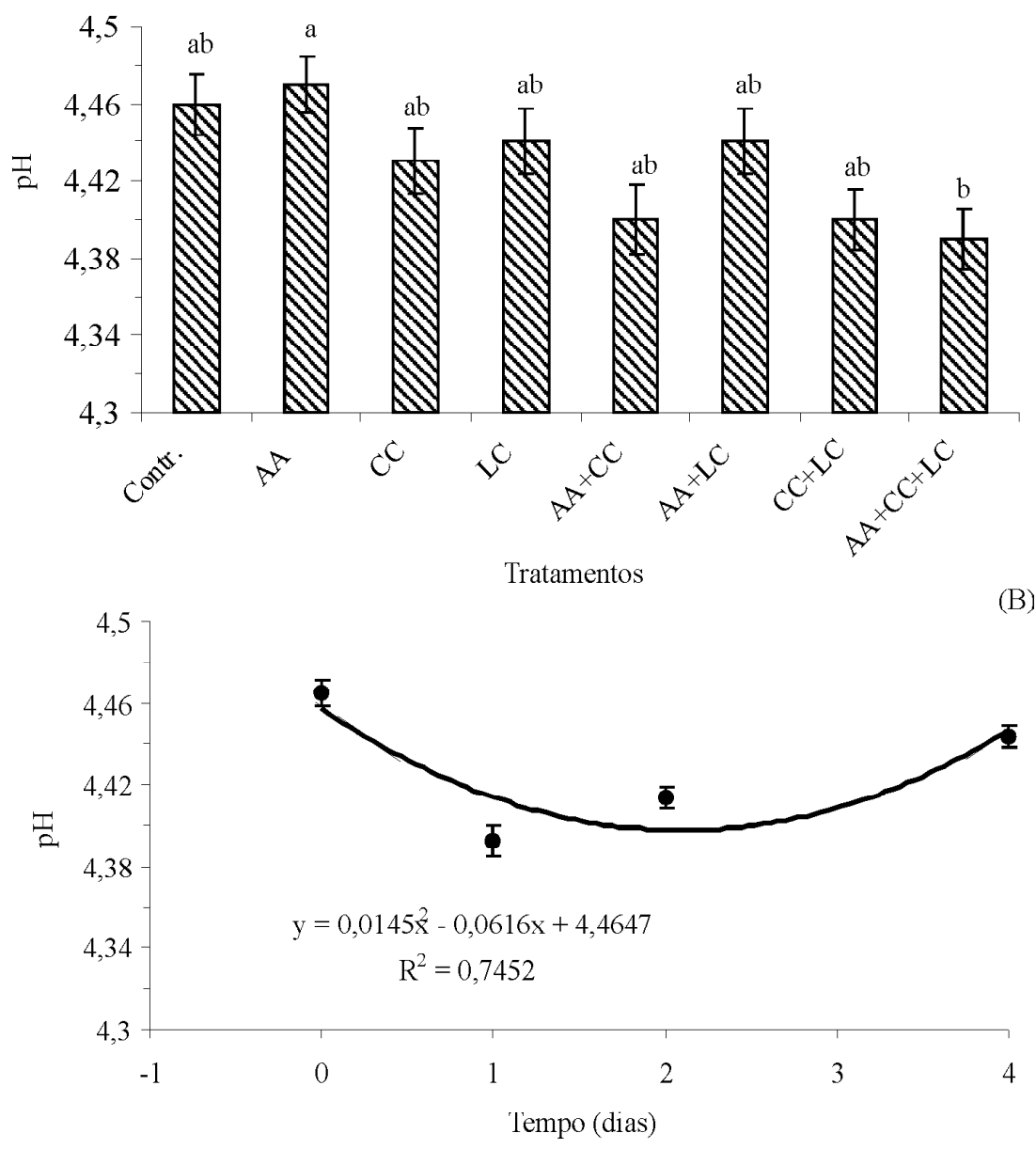

Figura 3 - Valores médios observados de $\mathrm{pH}$ de banana 'Maçã' minimamente processada submetida a diferentes tratamentos-controle; ácido ascórbico (AA) 1\%; cloreto de cálcio (CC) 1\%; cloridrato de L-cisteína (LC) 0,5\%; AA 1\% $+\mathrm{CC} 1 \%$; AA $1 \%+\mathrm{LC} 0,5 \%$; CC $1 \%+\mathrm{LC} 0,5 \%$; e AA $1 \%+\mathrm{CC} 1 \%+\mathrm{LC} 0,5 \%$, armazenada a $5 \pm 1{ }^{\circ} \mathrm{C}$ e $90 \pm 3 \%$ UR, por 4 dias. Barras verticais representam o erro-padrão das médias. Letras iguais não diferem entre si pelo teste de Tukey, a $5 \%$ de probabilidade.

Os valores $\mathrm{L}^{*}$ e o índice de escurecimento foram significativamente influenciados pelo período de armazenamento, pelos tratamentos e pela interação entre esses fatores. $\mathrm{O}$ valor $\mathrm{L}^{*}$ decresceu ao longo dos 4 dias de armazenamento (Figura $4 \mathrm{~A}$ ), contudo, os tratamentos que utilizaram L-cisteína na mistura foram mais eficientes em conter este decréscimo, o que foi expresso pelos menores valores $\mathrm{L}^{*}$, o que pode ser correlacionado com o menor índice de escurecimento observado nas fatias tratadas com cisteína, até o 2o dia de armazenamento (Figura 4 B). Os tratamentos 1 (controle) e 2 (ácido ascórbico 1\%) foram os menos eficazes em conter o escurecimento das fatias em relação aos demais, por apresentar os menores valores de $\mathrm{L}^{*}$ (56,04 e 57,01, respectivamente), em todo o período de armazenamento. Por outro lado, o tratamento 8 exibiu os maiores valores em todos os dias avaliados, com uma média de $(67,25)$.

Tal resultado sugere que o uso dos tratamentos em conjunto (tratamento 8) e que a presença da cisteína na mistura são mais eficientes na redução do escurecimento das fatias de banana. Os resultados encontrados estão de acordo com Gunes \& Lee (1997), que encontraram valores mais altos de L* em fatias de batatas tratadas com L-cisteína, ácido cítrico e ácido ascórbico. Gorny et al. (2002) também 
verificaram inibição do escurecimento proporcionada pela combinação de ácido ascórbico $2 \%$, lactato de cálcio $1 \%$ e cisteína $0,5 \%$, em pêras minimamente processadas. PerezGago et al. (2006) também verificaram redução no índice de escurecimento de maçã minimamente processada, tratada com cisteína $0,5 \%$, aplicadas tanto em solução aquosa como diluídas em coberturas protéicas comestíveis.

O valor $a^{*}$ (coordenada que varia do verde ao vermelho) aumentou com o tempo de armazenamento, em todos os tratamentos (Tabela 3). Com exceção do tratamento 8 , todas as fatias tratadas com L-cisteína $0,5 \%$ $(4,6$, e 7$)$ mostraram elevação acentuada de a* (surgimento de coloração rósea superficial) em maior intensidade, após o $2^{2}$ dia de armazenamento.

O "roseamento" observado nas fatias pode estar relacionado ao mecanismo citado por Richard-Forget et al. (1992), segundo os quais a ocorrência dessa coloração está relacionada à regeneração de fenóis, quando a quantidade de cisteína aplicada é baixa (relação cisteína/ fenólico no tecido menor que 1). Melo \& Vilas-Boas (2006) aplicando a mistura $\mathrm{CaCl}_{2} 1 \%$ + ác. ascórbico $1 \%$ + cisteína $(0,5 \%, 1 \%$ ou $1,5 \%)$ observaram que quanto maior o teor de cisteína na mistura, menor é a intensidade de "roseamento" de fatias de banana 'Maçã', expresso pelos menores valores de $\mathrm{a}^{*}$.

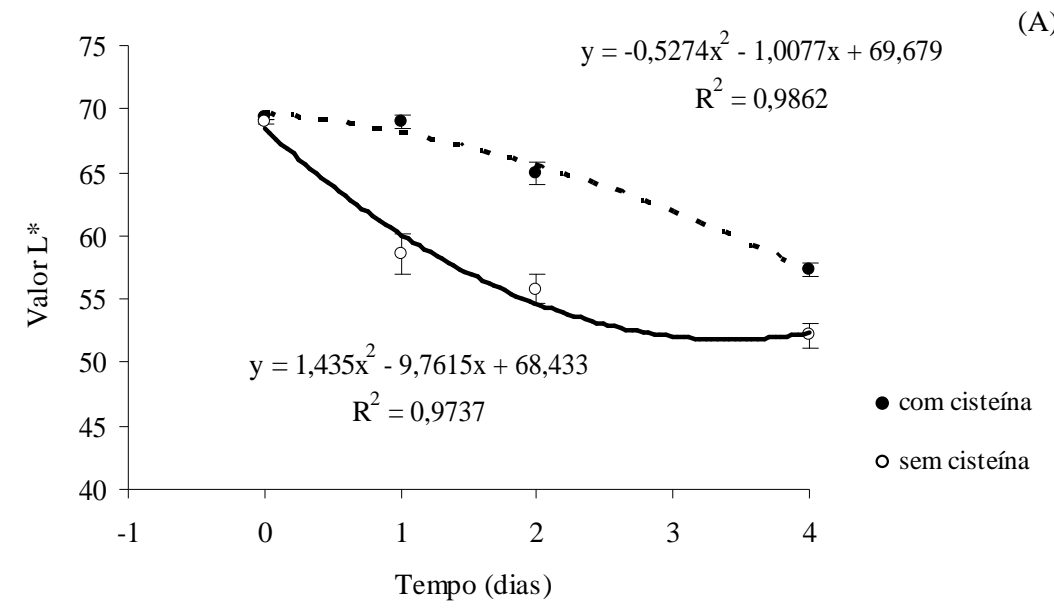

(A)

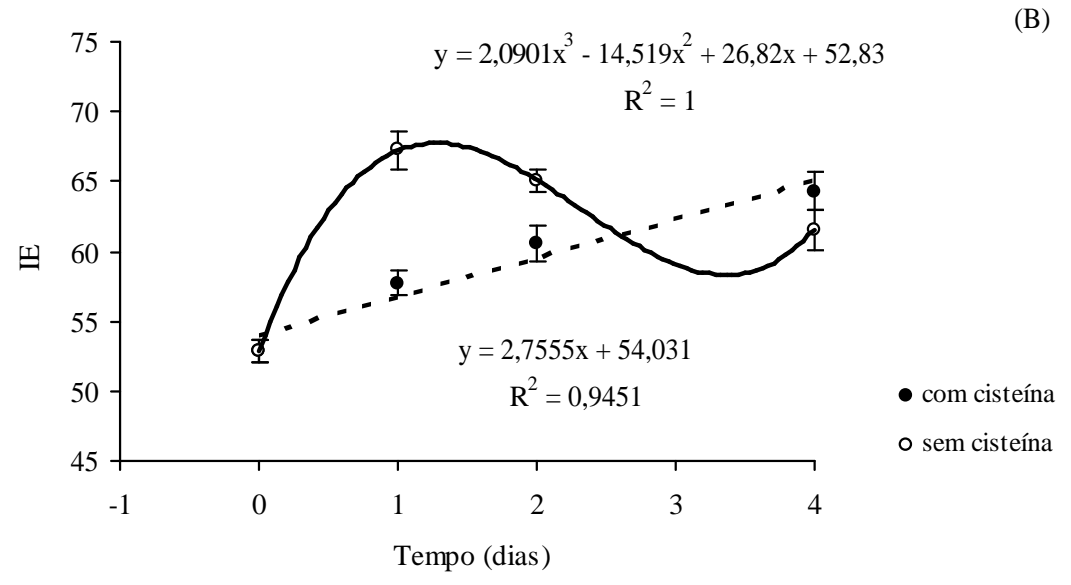

Figura 4 - Médias do valor L* e do índice de escurecimento (IE) dos tratamentos com cisteína e sem cisteína de banana 'Maçã' minimamente processada submetida aos seguintes tratamentos: controle; ácido ascórbico (AA) $1 \%$; cloreto de cálcio (CC) 1\%; cloridrato de L-cisteína (LC) 0,5\%; AA 1\% + CC 1\%; AA 1\% + LC 0,5\%; CC 1\% + LC 0,5 $\%$; e AA $1 \%+\mathrm{CC} 1 \%+\mathrm{LC} 0,5 \%$, armazenada a $5 \pm 1^{\circ} \mathrm{C}$ e $90 \pm 3 \%$ UR, por 4 dias. Barras verticais representam o erropadrão das médias. 
Tabela 3 - Médias do valor a* de banana 'Maçã' minimamente processada, durante o armazenamento a $5^{\circ} \mathrm{C}$ por 4 dias.

\begin{tabular}{lcccc}
\hline \multicolumn{1}{c}{ Tratamento } & $0 \mathrm{dia}$ & $1 \mathrm{dia}$ & 2 dias & 4 dias \\
\hline 1 - Controle & $-2,43 \mathrm{a}$ & $3,74 \mathrm{~d}$ & $3,79 \mathrm{~cd}$ & $4,31 \mathrm{ab}$ \\
2 - AA 1\% & $-2,43 \mathrm{a}$ & $3,01 \mathrm{~cd}$ & $3,39 \mathrm{~cd}$ & $4,73 \mathrm{abc}$ \\
3 - CC 1\% & $-2,43 \mathrm{a}$ & $1,81 \mathrm{c}$ & $3,45 \mathrm{~cd}$ & $4,61 \mathrm{abc}$ \\
4 - LC 0,5\% & $-2,43 \mathrm{a}$ & $-0,62 \mathrm{~b}$ & $2,51 \mathrm{bc}$ & $5,65 \mathrm{bc}$ \\
5 - AA 1\%+ CC 1\% & $-2,43 \mathrm{a}$ & $-0,66 \mathrm{~b}$ & $1,70 \mathrm{~b}$ & $4,07 \mathrm{a}$ \\
6 - AA 1\%+ LC 0,5\% & $-2,43 \mathrm{a}$ & $-2,16 \mathrm{a}$ & $1,56 \mathrm{~b}$ & $6,03 \mathrm{c}$ \\
7 - CC 1\% + LC 0,5\% & $-2,43 \mathrm{a}$ & $0,16 \mathrm{~b}$ & $4,25 \mathrm{~d}$ & $8,62 \mathrm{~d}$ \\
8 - AA 1\% + CC 1\% + LC 0,5\% & $-2,43 \mathrm{a}$ & $-3,53 \mathrm{a}$ & $-1,95 \mathrm{a}$ & $3,89 \mathrm{a}$ \\
\hline
\end{tabular}

Médias seguidas de mesmas letras na coluna não diferem entre si pelo teste de Tukey, a 5\%.

\section{CONCLUSÕES}

A utilização de aditivos químicos combinados, tais como $\mathrm{CaCl}_{2} 1 \%$ + ácido ascórbico $1 \%$ + cloridrato de Lcisteína $0,5 \%$ foi efetiva na manutenção da qualidade de 'Maçã' após o processamento mínimo, até o 4 dia de armazenamento a $5^{\circ} \mathrm{C}$. A aplicação de cloridrato de Lcisteína, na concentração de $0,5 \%$, determina desenvolvimento de coloração avermelhada nas fatias de banana.

\section{REFERÊNCIAS BIBLIOGRÁFICAS}

ASSOCIATION OF OFFICIAL ANALYTICAL CHEMISTRY. Official methods of analysis of the Association of Official Analytical Chemistry. 12. ed. Washington, DC, 1992.

BUTA, J. G.; MOLINE, H. E. Prevention of browning of potato slices using polyphenoloxidase inhibitors and organic acids. Journal of Food Quality, Wastport, v. 24, p. 271-282, 2001.

CHITARRA, M. I. F.; CHITARRA, A. B. Pós-colheita de frutos e hortaliças: fisiologia e manuseio. Lavras: ESAL/ FAEPE, 1990. 543 p.

DUDLEY, E. D.; HOTCHKISS, J. H. Cysteine as an inhibitor of polyphenol oxidase. Journal of Food Biochemistry, [S.1.], v. 13, n. 1, p. $65-75,1989$.

DZIEZAK, J. D. Preservatives: antioxidants: the ultimate answer to oxidation. Food Technology, Chicago, v. 40, n. 9, p. 94-102, Sept. 1986.

FENNEMA, O. R. Quimica de los alimentos. 2. ed. Zaragoza: Acribia, 1993. 1095 p.
GONZÁLEZ-AGUILAR, G. A. et al. Physiological and quality changes of fresh-cut pineapple treated with antibrowning agents. Lebensmittel-Wissenschaft undTechnologie, London, v. 37, n. 3, p. 369-376, May 2004.

GORNY, J. R. et al. Quality changes in fresh cut pear slices as affected by controlled atmospheres and chemical preservatives. Postharvest Biology and Technology, Amsterdam, v. 24, n. 3, p. 271-278, Apr. 2002.

GUNES, G.; LEE, C. Y. Color of minimally processed potatoes as affected by modified atmosphere packaging and antibrowning agents. Journal of Food Science, Chicago, v. 62 , n. 3 , p. $572-575,1997$.

HUXSOLL, C. C.; BOLIN, H. R. Processing and distribution alternatives for minimally processed fruits and vegetables. Food Technology, Chicago, v. 43, n. 2, p. 124-128, Feb. 1989.

KADER, A. A. Banana ripening chart: recommendations for maintaining postharvest quality. Disponível em: http://postharvest.ucdavis.edu/Produce/ProduceFacts/ iFruit/full banana_ripeningchart.shtml >1: Acesso em: 21 fev. 2008 .

KAHN, V. Effect of proteins, protein hydrolyzates and amino acids on o-dihydroxyphenolase activity of polyphenoloxidase of mushroom, avocado and banana. Journal of Food Science, Chicago, v. 50, p. 111-115, 1985.

KING JUNIOR, A. D.; BOLIN, H. R. Physiological and microbiological storage stability of minimally processed fruit and vegetables. Food Technology, Chicago, v. 43, n. 2, p. 132-135, Feb. 1989. 
MELO, A. A. M.; VILAS-BOAS, E. V. de B. Inibição do escurecimento enzimático de banana 'Maçã' minimamente processada. Ciência e Tecnologia de Alimentos, Campinas, v. 26, n. 1, p. 110-115, jan./mar. 2006.

MELO, A. A. M.; VILAS-BOAS, E. V. de B. Redução do amaciamento de banana 'Maçã' minimamente processada pelo uso de tratamentos químicos. Ciência e Agrotecnologia, Lavras, v. 31, n. 3, p. 821-828, maio/jun. 2007.

MOLNAR-PEARL, I.; FRIEDMAN, M. Inhibition of browning by sulfur amino acids: 3 . apples and potatoes. Journal of Agricultural and Food Chemistry, Easton, v. 38, n. 8, p. 1652-1656, 1990.

PALOU, E.; LÓPEZ-MALO, A.; BARBOSA-CÁNOVAS, G. V.; WELTI-CHANES, J.; SWANSON, B. G. Polyphenoloxidase activity and color of blanched and high hydrostatic pressure treated banana puree. Journal of Food Science, Chicago, v. 64, p. 42-45, 1999.

PEREZ-GAGO, M. B.; SERRA, M.; DEL-RÍO, M. Color change of fresh-cut apples coated with whey protein concentrate-based edible coatings. Postharvest Biology and Technology, Amsterdam, v. 39, n. 1, p. 84-92, Jan. 2006.

PINHEIRO, A. C. M.; VILAS-BOAS, E. V. de B.; TEIXEIRA, C. M. Uso de biofilme na conservação pós-colheita de banana 'Maçã'. In: CONGRESSO DE PÓS-GRADUAÇÃO DA UFLA, 12., 2003, Lavras. Anais... Lavras: UFLA, 2003. CD-ROM.

POOVAIAH, B. W. Role of calcium in prolonging storage life of fruits and vegetables. Food Technology, Chicago, v. 10, n. 1, p. 86-89, Jan. 1986.

REIS, C. M. F.; VILAS-BOAS, E. V. de B.; BOARI, C. A.; PÍCCOLI, R. H. Qualidade e vida de prateleira de banana prata minimamente processada. Ciência e Agrotecnologia, Lavras, v. 28, n. 3, p. 702-708, 2004.

RICHARD-FORGET, F. C.; GOUPY, P. M.; NICOLAS, J. J. Cysteine as an inhibitor of enzymatic browning: 2. kinetic studies. Journal of Agricultural and Food Chemistry, Easton, v. 40, n. 11, p. 2108-2113, 1992.

ROCCULI, P. et al. Effects of the application of anti-browning substances on the metabolic activity and sugar composition of fresh-cut potatoes. Postharvest Biology and Technology, Amsterdam, v. 43, n. 1, p. 151-157, Jan. 2007.

SAPERS, G. M.; MILLER, R. L. Browning inhibition in freshcut pears. Journal of Food Science, Chicago, v. 63, n. 2, p. 342-346, 1998.

VAROQUAUX, P.; LECENDRE, I.; VAROQUAUX, F.; SOUTY, M. Change in firmness of kiwifruit after slicing. Sciences des Aliments, Paris, v. 10, p. 127-139, 1990.

VILAS-BOAS, E. V. de B. et al. Características da fruta: banana pós-colheita. Brasília, DF: Embrapa, 2001. (Série frutas do Brasil, 16).

VILAS-BOAS, E. V. de B.; KADER, A. A. Effect of atmospheric modification, 1-MCP and chemicals on quality of fresh-cut banana. Postharvest Biology and Technology, Amsterdam, v. 39, p. 155-162, 2006.

WILEY, R. C. Minimally processed refrigerated fruits and vegetables. London: Chapman \& Hall, 1994. 357 p.

WILLS, R. B. H. et al. Postharvest: an introduction to the physiological and handling of fruit and vegetables. Kensington: New South Wales University, 1981. 161 p.

YANG, S. F.; HOFFMANN, N. E. Ethylene biosynthesis and its regulation in higher plants. Annual Review of Plant Physiology, Palo Alto, v. 35, p. 155-189, 1984. 